\title{
Why is cancer not a priority in South Africa?
}

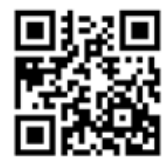

Every year on our planet, 8.2 million people die of cancer. $^{[1]}$ That number equals the population of a whole country such as Rwanda, Austria or Haiti. By 2050 it is estimated that the figure will more than double to approximately 17.5 million. ${ }^{[2]}$ As personal incomes increase in the developing world, lifestyles evolve towards the pattern seen in high-income populations, with obesity, excessive alcohol consumption, air pollution and smoking, all of which increase the risk of cancer. Already around $60 \%$ of all new cancer cases and $70 \%$ of related deaths occur in low- and middle-income countries. ${ }^{[1]}$

Globally, cancer kills more people than HIV/AIDS, tuberculosis and malaria. ${ }^{[2]}$ In the hierarchy of causes of death, it occupies a place close to the top in most countries.

Is the cancer incidence in South Africa (SA) following the global trend? Anyone who consults the latest list of all underlying causes of death (in 2013) in our country, published by Statistics South Africa recently, ${ }^{[3]}$ would be surprised to see that cancer does not appear among the ten most frequent causes. A cursory examination of the list may create the impression that SA enjoys the unique privilege of having been spared the increase in the incidence of malignant disease seen in the rest of the world.

For the more inquisitive mind, however, the joy would be shortlived, as it would soon become clear that malignant disease has been reported according to its anatomical location: 'malignant neoplasm of digestive organs', 'malignant neoplasm of respiratory and intrathoracic organs', and so on. The reporting was based on the International Statistical Classification of Diseases and Related Health Problems (10th edition) (ICD-10). ${ }^{[4]}$ As the ICD-10 does not provide for an all-encompassing 'malignant diseases' category, the total deaths from cancer are distributed over 15 anatomical sites, with the resulting smaller figures. Without disputing the epidemiological value of classifying malignant neoplasms by their anatomical location, when strategising for optimal healthcare delivery the total number of deaths from all these neoplasms would be required in order to understand the magnitude of the problem.

The total number of deaths from cancer in 2013, arrived at by adding together the numbers corresponding to various anatomical locations, was 36726 ( $8 \%$ of all deaths). This figure reveals that malignant neoplasms were in fact the second most frequent cause of death in SA, second only to tuberculosis. Also, cancer killed more people than other non-communicable diseases such as cerebrovascular pathology, hypertension and diabetes. This sobering finding has far-reaching implications.

First of all, the second place of cancer in the hierarchy of causes of death will have to be acknowledged. At present it does not even appear on the list of the ten most frequent causes. Thereafter, adequate planning followed by effective measures will be needed in order to address the already considerable and steadily increasing threat of malignant disease. Likewise, the top national research priorities should reflect the need for cancer control.

In order to increase our resolve to implement such significant changes, we need to evaluate the economic impact of cancer on SA more precisely. At present the magnitude of this impact in the country is not known, but the figures may be considerable. In the USA, where almost 600000 people die of cancer every year, the losses to the economy were estimated at USD216.6 billion in 2009. While the total healthcare costs were impressive at USD86.6 billion, the costs of lost productivity from premature deaths were even higher, amounting to USD130 billion. ${ }^{[5]}$ Worldwide, it has been estimated that cancer has the highest economic impact, from premature death and disability, of all causes of death. ${ }^{[6]}$ The total annual loss for the world economy was evaluated at USD1.16 trillion in 2010. ${ }^{[1]}$

A major contributor to the fight against the increased burden of malignant disease is the National Cancer Registry. Established in 1986 as a pathology-based registry, its activity was impaired by lack of funding and reluctance to communicate data on the part of numerous stakeholders such as private laboratories, among others, mainly out of fear of consequences arising from disclosure of information that could be regarded as private and confidential. ${ }^{[7]}$ The registry was revitalised in 2009, with the intention of transforming it into a hospital-based and later a population-based one. Although the reporting of cases was made compulsory by law in 2011, its completeness still needs to be tested. There remains a long distance to be covered to establishing a population-based registry. Continuing to face challenges, the registry has not yet processed its backlog of data since 2008, nor has it issued a comprehensive report.

A co-ordinated, evidence-based national approach to preventing and treating cancer is necessary today more than ever before. This should be framed by a National Cancer Control Plan, ${ }^{[8]}$ formulated along the guidelines established by the World Health Organization. ${ }^{[9]}$ The Cancer Association of South Africa undertook to formulate a cancer control plan as early as 1993. Although the plan was supported by representatives of academia, national medical research organisations, provincial administrations, hospice organisations and non-governmental organisations, it was not adopted by the National Department of Health until 1999. The National Cancer Control Plan is currently being updated, and although the Department of Health faces many new challenges, such as antimicrobial resistance, rapid implementation is expected to address the scourge of cancer.

It has to be acknowledged that a number of policies aimed at limiting the risk of malignant disease in SA have been implemented in the past two decades. The Tobacco Products Control Act and the Liquor Act have sought to limit the use of these recognised carcinogenic products. The cervical cancer screening programme and more recently the vaccination programme against human papillomavirus (in its pilot phase at present) will contribute to reducing the incidence of cervical cancer. ${ }^{[10]}$ Another significant measure was the establishing of the Ministerial Advisory Committee on Cancer in 2013. Further, the Department of Health's Strategic Plan for $2014 / 15-2018 / 19^{[11]}$ prioritises the fight against cancer of the cervix. The effectiveness of these measures needs to be evaluated by the National Cancer Registry.

In February 2014, the International Agency for Research on Cancer (IARC) launched the latest edition of a respected publication, the World Cancer Report 2014, ${ }^{[1]}$ which deals with numerous facets of cancer epidemiology, prevention, treatment and research. The most salient conclusion of this report was, as defined by one of its editors, Dr Christopher Wild, Director of the IARC, that 'we cannot treat our way out of the cancer problem. ${ }^{[12]}$ The costs of adequate treatments are progressively becoming unsustainable, even for high-income countries: ${ }^{[12]}$ cancer control must therefore resort to concerted action against the main risk factors - tobacco use, obesity and lack of physical activity, excessive exposure to sunlight, radiation, infectious agents, and chemicals in food and in the environment. Such action would require adequate policies, proper implementation and sustained monitoring, all supported by a comprehensive National Cancer Control Plan. 
The SA Medical Research Council (MRC) is poised to support research aimed at reducing the cancer burden. To this purpose, it plans to support research that provides reliable and up-to-date figures on the burden of cancer in our country to augment the surveillance measures. The MRC will also promote research into the prevalence and geographical distribution of cancer to better understand risk factors, as well as funding research addressing effective ways of mitigating the effects of carcinogens. Through its Strategic Health Innovation Partnerships division, the MRC is already funding translational research into new medicines and devices for the prevention, diagnosis and management of cancer. Addressing malignant disease as one of the national health priorities, the MRC will fund dedicated cancer centres in SA under the leadership of prominent scientists, which will respond to the most pressing and relevant cancer research questions.

The time has arrived to acknowledge the impact of cancer on the SA population, at present as well as in future decades.

The data published by Stats SA clearly place malignant disease as the second most frequent cause of death in our country in 2013. Death from cancer may rise to first place once tuberculosis and HIV have been more efficiently controlled. To improve the health of South Africans, adequate attention to cancer is required, and should include a holistic approach that addresses research, effective management and prevention modalities.

\section{Cristina Stefan}

Vice-President, South African Medical Research Council, and Visiting Senior Research Associate in the Nuffield Division of Clinical Laboratory Sciences, Oxford University, UK

\section{Corresponding author: D C Stefan (cristina.stefan@mrc.ac.za)}

1. Stewart BW, Wild CP, eds. World Cancer Report 2014. Lyon, France: International Agency for Research on Cancer, 2014.

2. American Cancer Society. Overview of the global cancer and tobacco burden, and our global programs. www.cancer.org/aboutus/globalhealth/ourglobalprograms/index (accessed 15 December 2014).

3. Statistics South Africa. Mortality and Causes of Death in South Africa, 2013: Findings from Death Notification. Statistical release P03039.3. Pretoria: Statistics South Africa, 2014.

4. World Health Organization. Classifications. International Classification of Diseases (ICD). www.who. int/classifications/icd/en (accessed 11 December 2014).

5. American Cancer Society. Cancer Facts \& Figures 2014. Atlanta, Ga.: ACS, 2014

6. American Cancer Society and Livestrong. The global economic cost of cancer. http://www.cancer.org/acs groups/content/@internationalaffairs/documents/document/acspc-026203.pdf (accessed 14 December 2014).

7. Singh E, Underwood IM, Nattey C, et al. South African National Cancer Registry: Effect of withheld data from private health systems on cancer incidence estimates. S Afr Med J 2015;105(2):107-109. [http://dx.doi.org/10.7196/ SAMJ.8858]

8. National Cancer Registry. www.nioh.co.za (accessed 15 December 2014).

9. World Health Organization. Cancer. National cancer control programmes. www.who.int/cancer/nccp/ en (accessed 15 December 2014).

10. Botha MH, van der Merwe FH, Snyman LC, Dreyer G. The Vaccine and Cervical Cancer Screen (VACCS) project: Acceptance of human papillomavirus vaccination in a school-based programme in two provinces of South Africa. S Afr Med J 2015;105(1):40-43. [http://dx.doi.org/10.7196/SAMJ.8419] 11. Department of Health. Strategic Plan 2014/15 - 2018/19. http://www.health.gov.za/docs/strategic/2013/ strategicplan.pdf (accessed 11 December 2014).

12. IARC Press Release No. 224. Global battle against cancer won't be won with treatment alone. Effective prevention measures urgently needed to prevent cancer crisis. http://www.iarc.fr/en/media-centre/ pr/2014/pdfs/pr224_E.pdf (accessed 12 December 2014).

S Afr Med J 2015;105(2):103-104. DOI:10.7196/SAMJ.9301 